\title{
A reflection about the social and technological aspects in flood risk management - the case of the Italian Civil Protection
}

\author{
M. del Carmen Llasat ${ }^{1}$ and F. Siccardi ${ }^{2}$ \\ ${ }^{1}$ GAMA (Meteorological Hazards Analysis Team), Department of Astronomy \& Meteorology, Faculty of Physics, University \\ of Barcelona, Av. Diagonal 647, 08028 Barcelona, Spain \\ ${ }^{2}$ International Centre on Environmental Monitoring Research Foundation and Department of Computer Sciences, University \\ of Genova, University Campus, Cadorna7, 17100 Savona, Italy
}

Received: 4 September 2008 - Revised: 24 November 2009 - Accepted: 29 November 2009 - Published: 19 January 2010

\begin{abstract}
The right of a person to be protected from natural hazards is a characteristic of the social and economical development of the society. This paper is a contribution to the reflection about the role of Civil Protection organizations in a modern society. The paper is based in the inaugural conference made by the authors on the 9th Plinius Conference on Mediterranean Storms. Two major issues are considered. The first one is sociological; the Civil Protection organizations and the responsible administration of the land use planning should be perceived as reliable as possible, in order to get consensus on the restrictions they pose, temporary or definitely, on the individual free use of the territory as well as in the entire warning system. The second one is technological: in order to be reliable they have to issue timely alert and warning to the population at large, but such alarms should be as "true" as possible. With this aim, the paper summarizes the historical evolution of the risk assessment, starting from the original concept of "hazard", introducing the concepts of "scenario of event" and "scenario of risk" and ending with a discussion about the uncertainties and limits of the most advanced and efficient tools to predict, to forecast and to observe the ground effects affecting people and their properties. The discussion is centred in the case of heavy rains and flood events in the North-West of Mediterranean Region.
\end{abstract}

Correspondence to:

M. del Carmen Llasat

(carmell@am.ub.es)

\section{Introduction}

Although individual earthquakes and hurricanes are the hazards that usually produce the greatest losses per event (Munich Re, 2006), floods and storms occur with such a temporal and spatial frequency throughout the world that, in total, they are the disasters responsible of the major economic and human losses (UNISDR, 2009a). In Europe the countries mostly affected by floods in the last decades were France (22\% of the total events in Europe) and Italy (17\%). Most of deaths were in Italy (38\%), Spain (20\%) and France (17\%) (Llasat, 2004). The 20th century flood inventory in Italy records nearly 3000 sites affected by at least one flood event during the period (Guzzetti et al., 1994). In fact, for Mediterranean Europe, floods are the natural hazard that produces, on the average, the major number of deaths and economic damages (Llasat, 2009; Estrela et al., 2000). To quote only a few cases, the flash flood event in North East of Spain on 25 September 1962, led to 441 deaths and 374 missing persons; the Piedmont flood on 16 October 1996, in North West of Italy led to nearly 100 casualties; and the Gard event, recorded on 8 and 9 September 2002 in the South East of France, produced 23 casualties (Legrand et al., 2003).

However, also in Mediterranean countries, the perception of the danger due to floods by the population at large is poor (Brilly and Polic, 2005). Floods are a hazard that tends to be viewed as natural and familiar, and these features may reduce the perceived seriousness of the hazard (Enander, 2005). A "this-won't-happen-to-me" attitude is sometimes overwhelming (Skiple Ibreek et al., 2005). Personal experience is the most important factor in the development of the perception of flood risk in people living in floodplains. In

Published by Copernicus Publications on behalf of the European Geosciences Union. 
fact, in communities with a "flood-culture," pre-event adaptations and adequate in-event responses minimize damages (Nunes Correia et al., 1998). The problem is that many inhabitants of floodplains do not know or do not care that they live in an area prone to floods. Skiple Ibreek et al. (2005) proved that less than half of the inhabitants of a floodplain in the United States were aware of this fact. The same was found in the UK (Kundzewicz and Mendel, 2003). Fordham (1992) suggested that inhabitants of floodplains most frequently take decisions in a condition of ignorance of their exposure. The problem increases when migratory movements to floodplains are produced.

That's the reason why most flood prone areas still increase in population density and change the land use into urban, affecting the flood regime and flood risk. In this sense, the floods increase detected in the North East coast of Spain is due to the increasing urbanization of areas close to rivers (Llasat et al., 2008).

To make citizens conscious of the risk they are exposed to a coordinated sequence of actions is needed. The first step is the evaluation of the probability that a given area could be flooded, the evaluation of the exposure of the inhabitants and the evaluation of the vulnerability for a given level of flooding in short scenarios of risk. The second step is the establishment of a system capable to detect and to analyze incoming events, and to forecast which scenario of risk will eventually develop: in short forecasting the scenario of risk conditional on the occurrence of a scenario of event. The third step is the establishment of a system capable to disseminate alerts or warnings, to be perceived as "efficient and true" by the population concerned, in order to produce the citizen consciousness, and to reinforce it if already present.

The social response, by a number of countries, has been the establishment of Civil Protection (CP) organizations during the last decades of the past century. UNISDR (2005) produced a sensible effort to speed up the process all around the world, taking into account historical and social differences. The coping capacity, understood as the ability of people, organizations and state systems to face and manage adverse conditions, emergencies or disasters (UNISDR, 2009b) is a characteristic of a given level of the social and economical development of the society: in European Mediterranean countries, for example, the right of the citizen to be safe and to be protected from disasters is presently acknowledged by the common law (i.e., Spain: Law 2/1985 21 January 1985 Civil Protection; France: Law Risk 30 July 2003; Italy: Law 225/92 and D.Law 112/98). In most of the less developed countries, where the human life is still threatened by the insufficient satisfaction of basic needs, CP dealing with the entire "end-to-end warning system" (UNISDR, 2009b) is not presently a priority.

In some countries CP is a self contained agency taking care of all the steps for the mitigation of the risk - in case of flooding: the mapping of risk areas, the prediction and the forecasting, the dissemination of warnings and eventu- ally the relief actions if needed. In other countries $\mathrm{CP}$ is a system of different agencies and state bodies, performing each some part of the process of risk mitigation. The first is the case of Italian CP, which, for instance, takes the responsibility to coordinate all the agencies and governmental organizations involved within the process, whilst, on the contrary, the Spanish CP is only responsible of approving all the plans related with emergency conditions, as well as managing the emergency, but the entire forecasting process is within the responsibility of the State Agency of Meteorology (AEMET, "Agencia Estatal de Meteorología"). The European Commission made efforts, and still is making, to support from the scientific and technological point of view the development of $\mathrm{CP}$ organizations in Europe, as well as the mechanisms involved in the early warning systems (i.e., the SAFER project (http://www.emergencyresponse.eu), developed in the frame of the Global Monitoring for Environment and Security initiative). Projects like DEDICS (Distributed Environmental Disaster Information and Control System $)^{1}$ and RADATT ${ }^{2}$ (Rapid Damage Assessment Telematic Tool), developed as early as within the EU Fourth Framework Program (19941999), where an example of such an effort. Also, the Interreg IIIB project, AMPHORE ("Application des methodologies de prevision hydrometeorologiques orientées aux risques environmentaux"), has analyzed and compared all the processes involved in the flood alert chain process in France, Italy and Spain (Llasat-Botija and Llasat, 2006).

The risk of flooding is presently one of the more mature areas, compared with other natural disasters, at least in the European Mediterranean areas. The research and technological innovation programs supported by EU and International Agencies got, on one side, an acceptable commonality of mutual understanding about basic concepts on risk mitigation, and, on the other side, provided disaster managers with numerical tools and models based on the different earth sciences, to make them capable to evaluate scenarios, forecast their severity and warn the concerned population.

The numerical meteorological forecasting of rainfall events, which stands at the root of each hydrological predicting process, has greatly improved in the last two decades (Zampieri et al., 2005; Martin et al., 2006; Collier, 2007). Global Circulation Models are getting down spacing scales of a few tens of km and Limited Area Models to a few km, the scale for resolving deep convective processes (Richard et al., 2003; Raiable et al., 2008). The routinely generation of an ensemble of many members of the numerical weather

\footnotetext{
${ }^{1}$ Project funded by the European Commission (DG XIII, Telematics for Environment), EN1003 the DEDICS project was undertaken by 11 partners from 6 European countries and coordinated by AIRMINES-Ecole des Mines de Paris. See http://cordis.europa.eu.

${ }^{2}$ Project funded by the European Commission (DG XIII, Telematics for Environment), EN1011, the RADATT project was undertaken by 7 partners from 3 European countries and coordinated by the University of Pavia. See http://cordis.europa.eu.
} 
forecast (Buizza et al., 1998; Wilson, 2000), jointly with the deterministic member, offers the opportunity for probability connotation of different possible scenarios of rainfall, giving way to the estimation of the probability of different scenarios of flooding risk conditional on the rainfall scenario.

The opportunity offered by the new forecasting tools, and the comparison between predictions and observations at space scales not possible till now, give also space for some basic considerations:

- how much predictable, at which scale in space and time, are the rainfall processes on which decision makers rely for decisions about the flooding risk conditional scenarios;

- how good is the predictive ability of the models when their resolution is lowered by an order of magnitude.

This paper try to offer some hints for a discussion we think absolutely needed, based on some, to now, marginal evidence of incongruities between numerical rainfall predictions and observations on the Italian area. The paper is organized as follows: in the first chapter some aspects of the historical perspective are summarized, whilst in the second one the concept of flooding risk scenario, jointly with the uncertainty of its different steps is described. In the third chapter the comparison of one season of numerical rainfall predictions and observations on the Italian peninsula is presented and shortly discussed.

\section{A historical perspective}

The concept of hazard was introduced in the semantics of European neolatin languages by a Florentine use of the Arabic word zara (the dice). In the Divine Comedy a play of dice frequent in Florence during the thirteen century is described as follows:

quando si parte il gioco della zara/colui che perde si riman dolente/repetendo le volte e tristo impara meaning that when the dice play is over/the looser stands downcast and sad/trying again and unhappily learning. (Dante, Div. Comm., Purg. VI.1)

The players used three dice, betting on the number that would appear, winning or loosing accordingly. However, if a number resulted smaller than six, or larger than fourteen, the looser had the right to scream zara, meaning null try, to consider null the try and to recover his money. The reason was that the probability, with three dice, to get a total equal to five or less, or equal to fifteen or more is so small that the range of possible outputs of each shooting was restricted to six-fourteen in order to make the play more fair.

From the Arabic word denoting the dice the word went into the Spanish azar, the Italian azzardo, the French hasard and the English hazard with a meaning we use now, to denote a very rare event. Nowadays, in the framework of natu- ral risks, the term "hazard" refers to the probability of occurrence within a specific period of time in a given area of a potentially damaging event. The probability of occurrence within a specified period of time, or the likely frequency, implies considering the relationship between it and a "measure" of the intensity of the threatening event (Lastoria et al., 2006). The UNISDR Terminology on Disaster Risk Reduction (2009b) defines the hazard as "a dangerous phenomenon... that may cause loss of life, injury or other health impacts..." describing it quantitatively by the likely frequency of occurrence of different intensities for different areas, as determined from historical data or scientific analysis. Following the UNISDR (2009b) definition, hazard is a component of a risk, the other components being the exposure, as the amount, if we restrict us to the impact on human life, of the stable or temporary residents in the exposed area, and the vulnerability, that considers the characteristics and circumstances that make the community susceptible to the damaging effects.

\subsection{A simple approach to flood risk management}

In the High Middle Ages, in many part of Europe, the ingenuity of humans was developing tools and procedures to protect villages and towns from the floods: a good example is the behaviour of the bourg master of the small medieval town of Finale (nowadays Finalborgo, the third borough of Finale Liguria and located further inland than Finale Liguria Marina, near Savona, Liguria, Italy, see Fig. 3). Finale, which belonged to the noble Del Carretto family, which ruled the area controlling the main access ways from West Liguria to Piedmont for the trade of salt, is a medieval town completely surrounded by walls, lying on the floodplain of the Aquila torrent (Fig. 1). The opening of the entrance of the western wall used to be the only way the Aquila River could flood the town. A simple system of barrages, or planks, was used to close the main gate whenever floods were feared. The decision to place wooden planks to prevent the river from flooding the town was made by the bourg master. His decision was based on scenarios analysis, it is to say, the adverse meteorological conditions and their potential impacts in the city. The scenario, or mental image, available to the bourg master for him to make the decision whether it was or not necessary to use the planks, which would have made the entrance inaccessible to carts, carriages and animals, was based on the experience of the previous floods which had brought havoc to goods stored in the town, killed animals as well as people. The bourg master's mind was functioning, like today, comparing future outcomes costs. He used to close the entrance when the fear of a possible scenario of flood was stronger than the possibility that no flooding would, after all, occur and he might be held responsible for the unnecessary use of the obstructing wooden planks. The rule that the bourg master used remained in a local saying: "Quando e nivue van au ma piggia a sappa e va a sappà, quando e nivue van au 


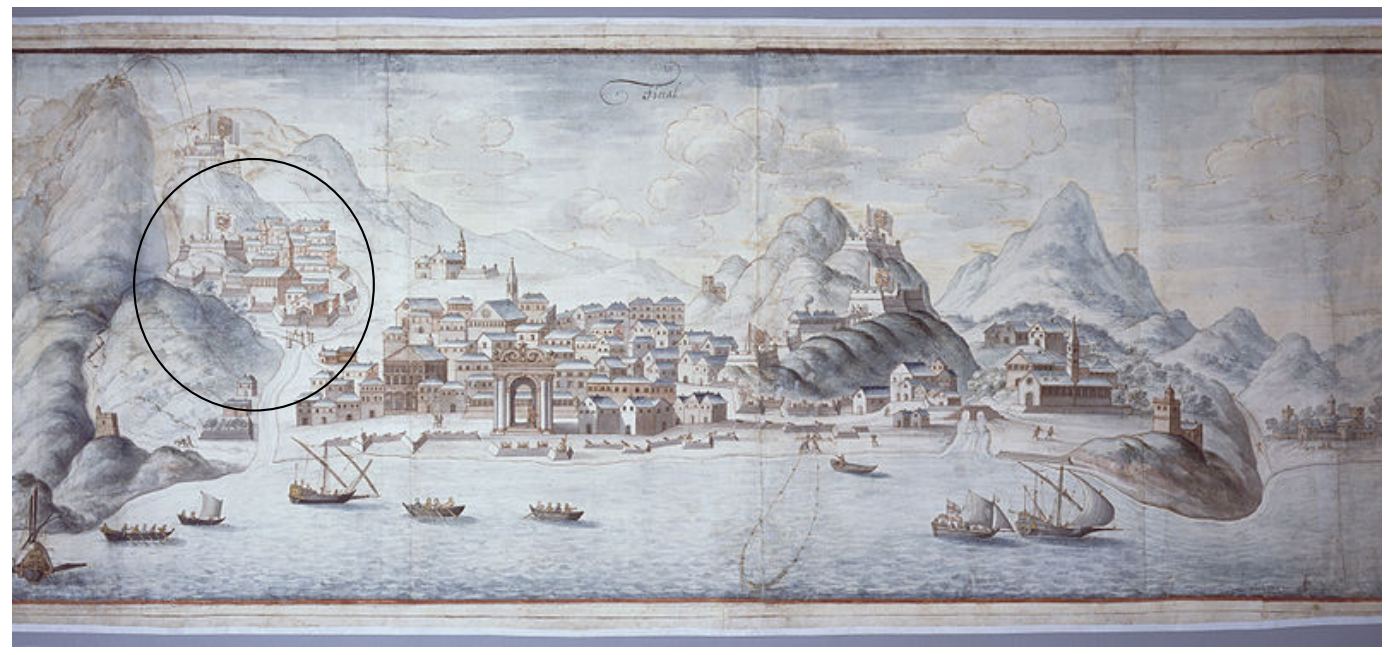

Fig. 1. The town of Finale in the 17th century. The old walled medieval town of Finale is signalled (source: Wikimedia Commons).

munte piggia a sappa e vatt'a scunde" or "when the clouds move towards the sea, take your spade and go to work/when they move towards the mountain, take your spade and find a good hiding place", describing the meteorological behaviour leading to rainfall extremes in that region.

The medieval wall that surrounded Barcelona city (Northeast of Spain) played a similar role in front of floods. Twelve main short water courses (ouadis), with a strong slope and non-permanent flow, traverse this plain in parallel. When heavy rains arise over or near the city, their overflowing can produce significant damage, and floods, landslides and temporary lagoons may be recorded. Although nowadays, most of these water courses are channelled in underground levels and belong to Barcelona's drainage system, in the Middle Ages flash floods could produce catastrophic damages. The first flood risk assumptions were experienced in the Early Middle Ages, occupying temporarily flooded areas and littoral lagoons. Flash floods affecting Barcelona and its surrounding region are very frequent, mainly in summer and early autumn (Barrera et al., 2006; Llasat, 2009). In some occasions they are so fast that people has not enough answer time. Consequently, the coping capacity to face flood disaster drove to take permanent preventive measures. An opened walled perimeter was designed with military function, but also to manage the floods, diverting flows out of the urbanised quarters (Barrera et al., 2006). Figure 2 shows the wall perimeter at the Early Modern Age and the twelve main short water courses that traverse the plain where Barcelona is placed. In this figure is possible to appreciate the role of the city wall modifying some water courses as well as the potential role of some bastions as defence in front of the floods. Following the documentary sources, in the occasions that rivers overflowed with high energy against the walled perimeter and part of it was destroyed, the authorities deemed this damage acceptable, because the flooding did not produce major damages into the village (Barriendos and Martin Vide, 1997; Barriendos et al., 2003). The main difference with the town of Finale was that in this case the bastion was a permanent structure and the authorities' consider it like a preventive measure to avoid or mitigate the flood impact.

The burgmaster of Finale took his decision based on scenarios analysis, like today. The main difference was that his knowledge was based on traditions and cultural heritage, and nowadays, scenarios can be obtained from deterministic or probabilistic approaches based on numerical or statistical models. The Barcelona authorities took their decision knowing the high frequency of scenarios favourable to flash floods in this city, applying structural measures; nowadays, flash floods prevention in this region is based on a combination of structural and non-structural measures.

The idea is simple. In order to take effective civil protection actions - even more important nowadays in our much more complex society - it is mandatory to be provided with scenarios, both detailed and concise - according to the safeguard objectives -, that can be comprehended and shared.

\subsection{Scenarios of event and scenarios of risk}

Most Civil Protection organizations today agree on the UNISDR (2009b) definition of risk scenario. Restricting us, for sake of simplicity, to human life, a scenario of risk, as already stated, is the amount of damage people can suffer over a specific area in a specific period of time given the occurrence of a foreseen hydro meteorological event on such an area and time ${ }^{3}$.

\footnotetext{
${ }^{3}$ Beyond the traditional scenarios due to high intensity rainfall (i.e. floods and landslides), the scenario of an event can relate to a meteorological pattern characterized by conditions that can trigger and propagate fire in rural and wooded areas. It may also relate to violent sea storms bringing havoc to beaches, costal villages and
} 


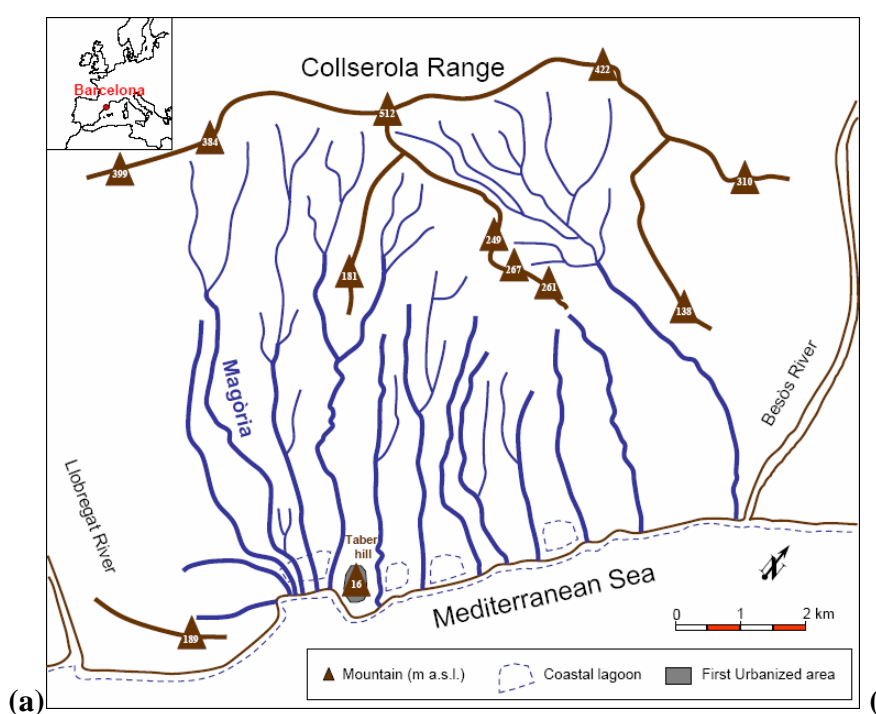

(a)

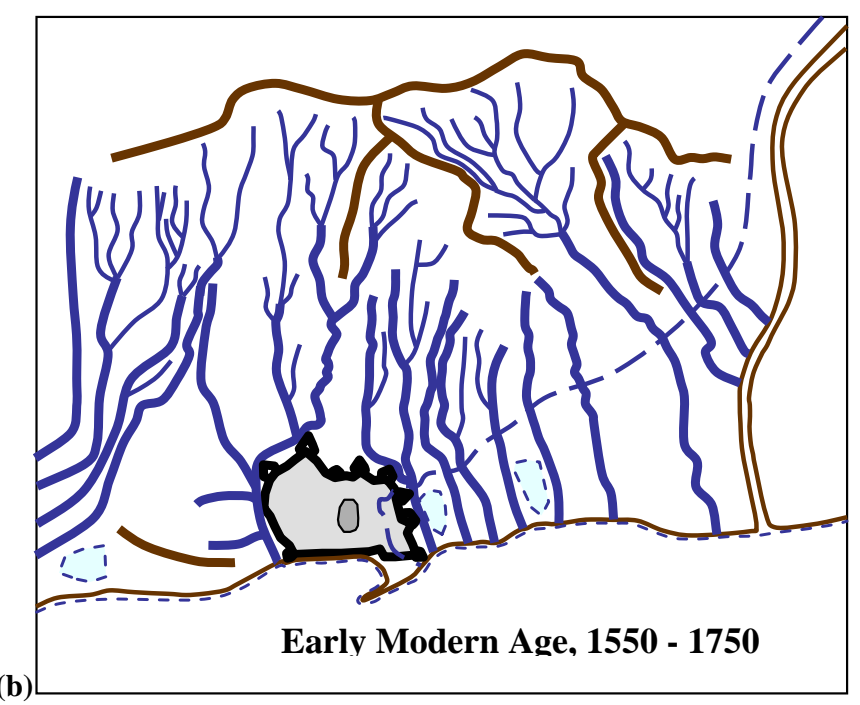

Fig. 2. (a) Water courses in Barcelona county under natural conditions. (b) Water courses modification and city wall corresponding to period AD 1550-1750 (adapted from Barrera et al., 2006).

Then, the concept of scenario of risk is the same, nowadays and some centuries ago, as has been presented in the previous chapter, but the great difference resides in the knowledge of the phenomena, the available tools to forecast and monitoring the event, or the emergency management. Vulnerability has also changed a lot. Some structural measures have been applied in developed countries in order to decrease the vulnerability, but the level of potential losses that the society considers acceptable has decreased considerably.

\section{Events, scenarios of flood risk and their probability of occurrence}

The probability of occurrence of a scenario of risk is the probability of occurrence of that amount of damage to people and properties given the occurrence of the event. It is, there-

towns, sea front access ways and port facilities. It may even relate to heavy snowfalls affecting road, railway systems and airports. Besides the impact on inhabited areas, the impact on essential and industrial structures must be also examined since such events can cause damage to people and properties within an integral scheme of systemic vulnerability. In fact, forest fires can reach and damage a refinery plant whose explosion might affect homes; or a flood can make the road system of a town inaccessible thus preventing the inhabitants from fleeing from the area and it can also make a hospital non-operative if the electricity supply to the hospital has been cut off due to the location of the hospital in the flooded area. Besides this, great indirect damages can be produced as a consequence of the work disruption in companies and industries, consequences in the health of some people affected by the disaster (both psychological and physical), and so on (Messner and Meyer, 2006). fore, necessary to determine the probability of the scenario of risk conditioned to the scenario of event and, on the other, the unconditioned probability of the scenario of the event.

That a Civil Protection Agency be able to issue warnings to possible affected population on a basis of a sound probabilistic procedure is of foremost importance from a social point of view. That a probabilistic procedure is formally established is, in some a way, similar to the existence of the traditional rule of the burgomaster we mentioned before. It's a safeguard for the decision maker in respect of his liability. On the other side to know that the warnings are issued on sound procedures produces consensus toward the Authority, helping consensus on restrictions of land and properties use.

We try now to make a bit clearer, through the use of simple examples, the concept of a scenario of event and its probability of occurrence. We would like to clarify, also for non disciplinary experts, how the chain to predict scenarios of flood event is constructed, and how inherent uncertainty affects each step of the chain. We will start with the example of the hydrological predictions, but we will enlarge rapidly the scope to multidisciplinary predictions, shortly including meteorology of rainfall extremes, hydrology of catchments, hydraulics of river flood and hydraulics of alluvial plains. The aim is to encourage scientists in different disciplines to find a way to suggest comparable measures of the uncertainty amount in each field.

Let us start with hydrological predictions. Let us refer to a specific river basin, for instance the Tiber River, and let us consider one section in particular, that one of the Ponte Milvio in Rome. Flood waves are possible at the Ponte Milvio. When this happens, hydrologists, then, state that in the Tiber River at the Ponte Milvio a flooding event has taken 


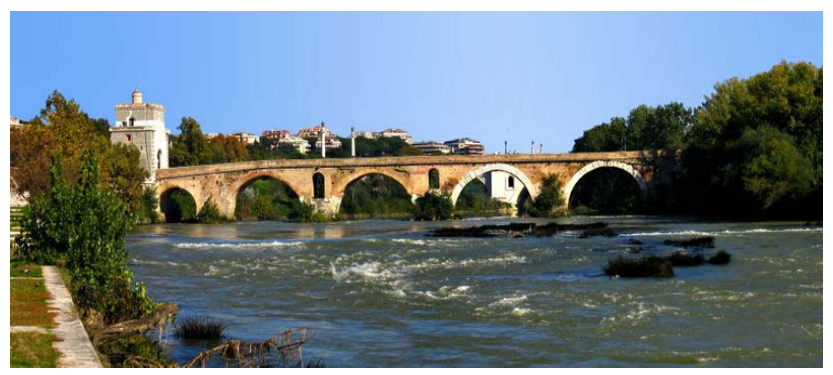

Fig. 3. Side view of Ponte Milvio and the Tiber River, Rome (source: A. Majanlaht, 2005, Wikimedia Commons).

place. However, they are more interested in evaluating the uncertainty of how serious future floods are likely to be. Hydrologists follow this procedure: every year, every day of the year, they observe the river level and register the maximum flood peak of that year. As a matter of fact, every year, they repeat the experiment of observing the river maximum flow. For each individual year they obtain a specific result of the random variable maximum annual flow rate of the River Tiber at the Ponte Milvio. The set of all possible results gives the sample space of the event of a possible flood of whatever value of the Tiber River at the Ponte Milvio. They, then, organize data in an increasing order. If the number of the experiments - i.e. years of observation - is enough, they, then, quote out in the classic way, or infer, the probability that, in the next experiment which has not been carried out yet, the flow rate is larger than given threshold. Such probability is estimated as the observed frequency of the observed maximum annual flow that exceeded the threshold in the past. Established procedures allow evaluating the uncertainty of such estimates.

In reality, the concept of event is more complex. The physical quantity to be observed is not only the maximum flow rate. It's also its evolution in time, i.e. the hydrograph, the contextual rate of bed load, which importantly affects the river bed, the contextual rate of the load floating on the surface, which also importantly affects the capacity under bridges or structures supported by pylons in the riverbed. Therefore, the flooding event cannot be described by one scalar variable only. The experiment must be enriched with a vector of measurements besides those of the maximum flow rate: measurements of the flood volume, its duration, the presence or absence of material either at the bottom or on the surface and the amount of such material. Such measurements are not all available for the major part of the past events. It is, therefore, impossible to infer their probability on the basis of the observed frequency. In such case, the word "probability" must be understood, instead of that one which is based on observed frequency of the results, as that one which is based on the expectancy as perceived by the competent expert. In fact, the hydraulic engineer expects, in the case of modest peak flow rates - i.e. after rainfalls of small entity with moderate saturation of the mountain slopes - the rate of load carried by the current on the bottom to be very small and the rate of load floating on the surface to be negligible. In both cases the competent expert considers the occurrence of landslides, due to slope sliding and contributing solid material and vegetation to the riverbed which is, then, dragged downstream, improbable. Contrary, when maximum flow rates are of high entity, and, therefore, the flow rates forming the rising branch of the hydrograph are of high entity too, the competent expert expects surface slides to be a lot more likely, phenomena of erosion and transport to be more relevant and the on-surface transport of shrubs, tree trunks and brushwood to be extremely likely. The best practices of the hydraulic engineering allow evaluating the uncertainty affecting such estimates, frequently by the use of traditional safety factors.

The real situation is even more complex because the hydraulic evaluations are only part of the problem. In fact we should define an event as the ensemble of a number of realizations: we shortly list them hereinafter with some notes about the observation availability of the processes and the tools to observe them.

- A pattern of adverse meteorological conditions leading to heavy rainfall, that can be observed or forecasted by meteorologists, using all the available meteorological information (radiosounding, satellites, meteorological radar,...). In this case rainfall data provided by the meteorological models have a low resolution to be applied to hydrological models (Turato et al., 2004);

- A heavy rainfall pattern distributed over a basin or ensemble of basins (hydrologists could observe that through a traditional network of rain gauges and/or remote sensors like meteorological radars at ground or flying on satellites) (Molini et al., 2006; von Hardenberg et al., 2007; Fiori et al., 2009);

- A more or less complete saturation of mountain slopes (pedologists could observe that through direct surveys, which are quite difficult in real time, or remote sensors flying on satellites);

- An ensemble of stream floods, whose peak flows may be relevant in consideration of the draining capacity of the longitudinal and transversal works (hydraulic engineers could observe them through traditional hydrometric stations reporting in real time) (Gabellani et al., 2007);

- More or less extended landslide processes of the surface type can be associated, producing solid transport and more or less relevant surface-carried material (geologists could observe them through direct surveys which are quite difficult in real time, or remote sensors flying on satellites); 
- Flooding phenomena of perifluvial areas, over one or more basins and over one or more sections, can be associated (people working in civil protection could observe that through direct surveys or remote sensors flying on satellites);

However, only few cases exist in which observations have been so complete and, most of all, the experiments have been repeated so often over one individual site, luckily, to obtain correct statistics allowing inferring the probability of each one of the components conditioned upon the occurrence of the previous one. The same obviously apply to the uncertainty.

Therefore, from what has been described so far, we are compelled to replace the observation of the results of the same experiment over a specific section - experiment which does not come with the desired numerosity - with the simulation of the chain of physical processes in which, starting with a predicted weather pattern, the distribution of a conditioned probability of a flood of extension and depth superior to a critical threshold can be numerically rated (Ferraris et al., 2002; Siccardi et al., 2005).

For each flood-prone area of each country, the above described procedure could be repeated as often as necessary, with different expressions and values of the parameters of probability distributions, in order to build, out of simple enumeration, the probability-conditioned distributions of the desired random variables. Or, in real time, by simulation of the chain of the physical processes, from meteorology to flooding for which, however, we should get from experience the probability-conditioned distributions of the parameters. The numerical representation of the chain of physical processes is obviously critical.

Now the question is: do we have knowledge and tools to perform such a task? To what extent of space and time detail?

\section{An operational probabilistic chain}

\subsection{The conceptual scheme}

Many attempts have been made in many countries to build up a sound operational probabilistic chain, mostly in Europe and Western US (Buizza et al., 1998; Chancibault et al., 2006; Apel et al., 2006). The major issues arise: how large is the uncertainty on the simulation of each single physical process, and how to propagate the uncertainty through the chain (Wood and Rodriguez-Iturbe, 1975; Cullen and Frey, 1999; Ferraris et al., 2002; Siccardi et al., 2005; Molini et al., 2006; Diomede et al., 2008; von Hardenberg et al., 2007; Collier, 2007; Fiori et al., 2009).

The Italian Civil Protection has recently made an attempt to build up a predictive chain to be used everyday, for the purpose of alerting people about floods and inundations and diffuse landsliding processes, as well as, for the high probability of forest fires. The predictive chain includes the avail-

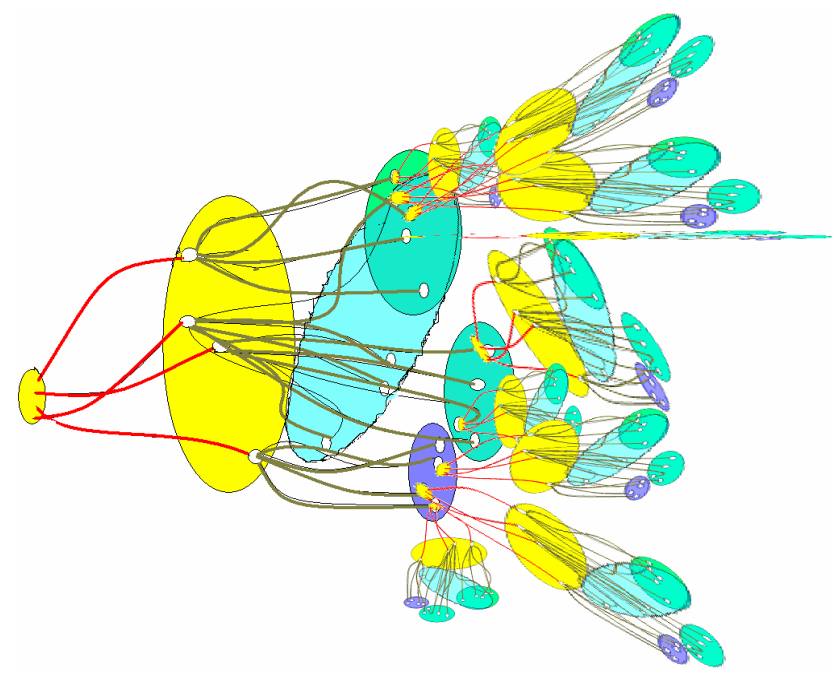

Fig. 4. The scheme for the increasing uncertainty (based on Siccardi and Tibaldi, 2006).

able ensemble of the numerical weather predictions and the rainfall/runoff forecasts on rivers crossing the target area; just recently the real-time observed degree of saturation of the slopes has been included (Siccardi et al., 2005; Molini et al., 2006). Figure 4 conceptually represents the predictive chain and its uncertainty production. It is a re-interpretation of the one Stefano Tibaldi (Siccardi and Tibaldi, 2006) designed to represent the uncertainty of the meteorological numerical prevision of ensemble.

Each member of the meteorological ensemble (here only four in order to make the drawing not to much confused), is represented by the red line connecting the small yellow oval on the left to the large one immediately on the right, which contains the space-time conditions - white dots- predicted by each ensemble member. From each of them, four different space-time precipitation histories - black lines - lead to different space-time conditions of saturation of the slopes of different watersheds, their space denoted by different shades of green-blue. From them, possible realizations of the riverbed flow originate, leading, further to the right, to different spacetime(s) hydrographs where different peak flow value occur. From each of them, different realizations of floods originate, in different space-time conditions, different areas with different severity.

The picture is aimed to conceptually show the possible cause chain transferring and increasing the initial uncertainty by combining it with the uncertainty of the following processes (Siccardi et al., 2005). At each step, the rate of uncertainty can be transferred to the following step through the probability rate of the single realization-probability which is an appropriate combination of the probability intended as the observed frequency and of the probability intended as the expectancy of the competent person. 


\subsection{Probability of rainfall events}

In the above discussed predictive chain, the reasoning always moves away from the meteorological forecasting. In fact, it is generally expected to come across a possible result of a flooding, for which the floods forecasting cannot simply be based on ground measurements. That's exactly the case for every large number of Mediterranean catchments, where the hydrological response time is very short, and frequently much shorter than the social response time to be alerted and to build up precautionary actions (i.e. Morin et al., 2006; Barnolas et al., 2009). Therefore, a numerical prediction of rainfall depth, not fallen yet, becomes necessary. Hydrologists have to use rainfall predictions instead of rainfall observations (i.e., Diomede et al., 2008; Llasat et al., 2009). Only for large catchments, rainfall forecasting can be obviated.

Our perception is that the numerical meteorological rainfall predictions are affected by an uncertainty range much larger than in any other physical process we just mentioned before, and, more importantly, no common procedure is available to estimate the width of such range ${ }^{4}$. In order to improve it, the EPS (Ensembles Prediction System) is being tested by different meteorological services (like the Spanish one, AEMET,"Agencia Estatal de Meteorología") in order to analyze their operational applications in short term forecasting (Ramos et al., 2007; García-Moya et al., 2008).

A field of rainfall meteorological predictions should, therefore, be characterized by, besides a nominal resolution, a reliable scale too. By reliable scale we mean the time and space scale below which a prediction is characterized by an uncertainty unacceptable for forecast aims. This definition, more than formally satisfactory, is, in reality, an operational

\footnotetext{
${ }^{4}$ In fact, errors increase during the calculation process of the prediction, adding to one another and combining with the errors contained in the formulation of the equations and in the used mathematical methods. Somewhere along the prediction process, the increasing errors make the predictions themselves of little or no practical use at all. Nowadays, the limits of our observational and modelistic systems and the physical-mathematical nature of the atmosphere - which causes the increase of the errors to be guided by chaotic dynamics - set the practical time limit of use of meteo-numerical predictions over a few days, typically more than five and less than eight days. In the case of rainfall, which is one of the most difficult observable phenomena to forecast because of its great and complex space-time variability, such limit, unfortunately, further shrinks down.

On the other side global operational methods of prediction of ensemble are nowadays limited, basically because of the scarce availability of resources of numeric calculation, to the space resolutions of the dimension of a few hundred kilometres and time resolutions of the dimension of ten hours. Higher resolutions can be achieved with local ensembles obtained through nowadays operational models at limited area, which, nested on the previous ones and by operating over a reduced area, develop the atmospheric dynamics at scales of the dimension of ten kilometres in space and few hours in time.
}

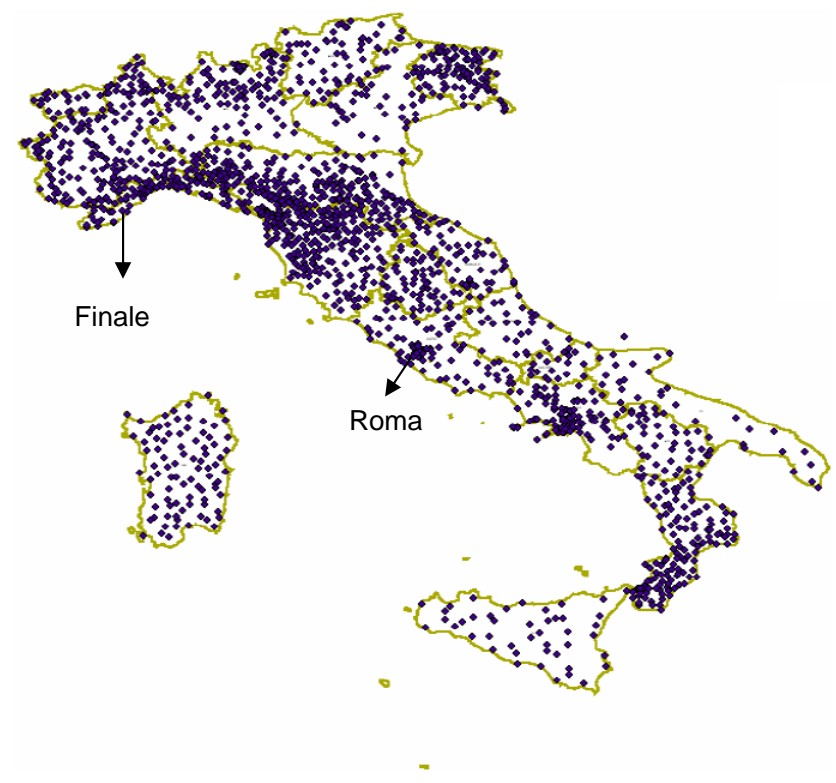

Fig. 5. The Italian raingauges reporting network and the location of the Italian places cited in the text.

one. In this sense, some important advances in the field of the predictability (the degree to which a correct prediction or forecast of a system's state can be made either qualitatively or quantitatively) has been done in recent years (Rice et al., 2004; Rotunno, 2008; García Moya, 2008).

\subsection{The Italian network of observation and the first year of results}

Many attempts have been made, particularly by a group of scientists working upon financing by the Italian Civil Protection, in order to retrieve, from comparison between rainfall observations and predictions, the so-called reliable scale. We would not, here, report all the experiments and the discussions. We would like only present the first results.

Due to the investments of the past years, the reporting rain gauges network of Italy is quite dense: there are approximately 1200 hourly reporting rain gauges in an area of $301338 \mathrm{~km}^{2}$ (Fig. 5). An archive of hourly rainfall depth is presently available for recent years: the density is between $1 / 50 \mathrm{~km}^{2}$ to $1 / 300 \mathrm{~km}^{2}$ with an average of $1 / 100 \mathrm{~km}^{2}$, density completely comparable with the space resolution of some operational Limited Area Models (i.e., MM5, COSMO-LAMI, HIRLAM,...).

Figure 6 shows the relationship between observed and model-predicted rainfall for 15 COSMO-LAMI CRM (cloud resolving models) (Steppeler et al., 2003; Chancibault et al., 2006; Vincendon et al., 2007) forecast experiments over all Italy during 2006 (Molini et al., 2006, 2007). It reports the observed total amount of rainfall averaged on basin's area (on the $\mathrm{x}$-axis) compared with the rainfall depth predicted by the 15 simulation experiments (on y-axis). The sample 


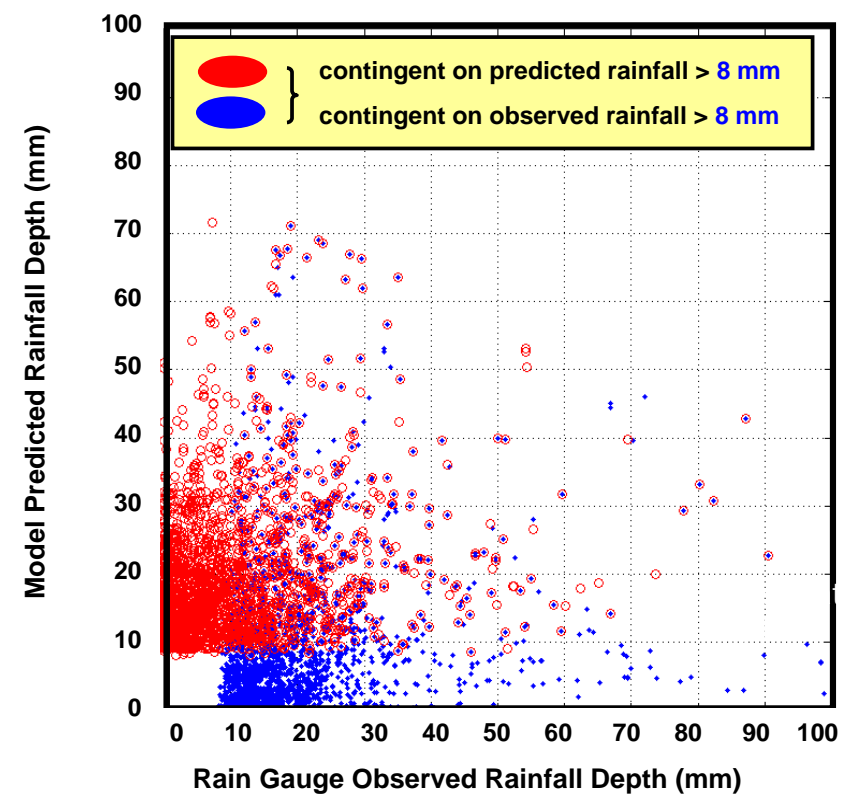

Fig. 6. Observed rainfall depth versus predicted ones, hydrological year 2006 .

is composed by all the events exceeding $8 \mathrm{~mm} / 24 \mathrm{~h}$ averaged in space over 150 watersheds of the Italian territory of area between $1000 \mathrm{~km}^{2}$ and $5000 \mathrm{~km}^{2}$, for the period AprilDecember 2006. Blue dots denote events chosen on the basis of the observed rain whilst red dots denote events chosen on the basis of the predicted rain. The null zone in the graph has been created by requiring to the predicted (or observed, in the case of blue dots) rainfall depth to exceed the accumulation threshold of $8 \mathrm{~mm}$ before confirming rain event of potential interest for Civil Protection. The accumulation threshold (T in $\mathrm{mm}$ ) is defined as product of characteristic intensity (I, in $\mathrm{mm} \mathrm{h}^{-1}$ ) and the characteristic watershed time of response (TR, in hours), i.e., $\mathrm{T}=\mathrm{I} \times \mathrm{TR}$. Using basins of areas above of $1000 \mathrm{~km}^{2}$ with a characteristic intensity of $1 \mathrm{~mm} \mathrm{~h}^{-1}$ and a characteristic TR of $8 \mathrm{~h}$ yields a characteristic T of $8 \mathrm{~mm}$. A total of 5526 point comparisons for the 15 experiments have been made. The models have an horizontal resolution of $7 \mathrm{~km}$, then the spatial scale of point comparison is of $7 \mathrm{~km}$.

The comparison apparently is not encouraging: the correlation of predictions and observations, at least for the period under examination and for the range of catchments observed, is practically non existent. The figure mainly denotes an overestimation that could be partially explained by the different spatial scales of predicted $(7 \mathrm{~km})$ and observed rainfall (averaged over the basins). Red dots concentrated on the left side might be considered false alarms, and blue dots concentrated at the bottom of the figure show the cases for which predicted rainfall was less than the actually observed. The complete explanation of this figure would require a deeper analysis because it includes events of different scales, recorded in different seasons of the year and for dif- ferent watersheds. Besides this, a rigorous analysis based on physical, microphysical, dynamical and kinematical aspects of rainfall processes and their modelling would be needed.

Following this discussion, the contingency score for 2006 ordinary risk scenarios in Italy shows that from a total of 99 events predicted by the Italian Civil Protection system, 77 of them were observed meanwhile 15 observed events were not predicted. This score decreases when we refer to high risk scenarios: only the $50 \%$ of the operationally predicted events were observed meanwhile a $35 \%$ of the observed events were unpredicted (Molini et al, 2006).

\section{Conclusions}

The concept of scenario of risk is the same, nowadays and some centuries ago, but the great difference resides in the knowledge of the phenomena, the available tools to forecast and monitoring the event, and the emergency management. A modern Civil Protection, in a modern, post-industrial society, has two major tasks: the first one is sociological, in the sense that the new organization has to deeply intermingle with the existing social institutions in order to get consensus on the restrictions of land use and other limitations; the second one is technological, in the sense that Civil Protection (or the respective Agencies responsible of the forecasting and hazards monitoring) must make use of the most advanced and efficient tools to predict, forecast and observe the ground effects affecting people and its properties, in order to safeguard lives and properties, and to make the Authority perceived as much reliable as possible. But this reliability can be very affected by the uncertainties associated to the forecasting and prediction process. This is the case of floods in Mediterranean Region. Usually they are flash floods associated to high rainfall events, where the uncertainty affecting the rainfall forecasting plays a major role in the warnings. This uncertainty depends on the meteorological model applied, their initialization and parameterization, the spatio-temporal features of the stormy event and so on. Besides this, the uncertainty associated to the rainfall field is propagated in the hydrometeorological chain, and it makes more difficult the decision process.

We would like not to comment any more, but to leave to the discussion the question we used to open the chapter: is that a technological fantasy, to think to be capable to build tools to predict scenarios of inundation and diffuse landsliding? A technological fantasy, we mean, to be cancelled by future projects of Civil Protection Organizations or Hydrometeorological Agencies? Or do we have to continue putting pressure on the atmospheric scientists, hoping that assimilations of observations into numerical meteorological models of the atmospheric processes will give us a manageable final tool?

Acknowledgements. The present study has been supported by the European Project FLASH (FP6-2005-Global-4 n. 036852) and 
by the Italian Civil Protection Dept. under the Proscenio research project 2006-07. Our thanks to Eric Smith and Amita Mehta, for the improvements of the analysis to the COSMO-LAMI rainfall prediction experiment data.

Edited by: F. Guzzetti

Reviewed by: L. Garrote and another anonymous referee

\section{References}

Apel, H., Thieken, A., Merz, B., and Blösch, G.: A probabilistic modelling system for assessing flood risks, Natural Hazards, 38(1-2), 79-100, 2006.

Barnolas, M., Rigo, T., and Llasat, M. C.: Characteristics of 2-D convective structures in Catalonia (NE Spain): an analysis using radar data and GIS, Hydrol. Earth Syst. Sci. Discuss., 6, 47054736, 2009, http://www.hydrol-earth-syst-sci-discuss.net/6/4705/2009/.

Barrera, A., Llasat, M. C., and Barriendos, M.: Estimation of extreme flash flood evolution in Barcelona County from 1351 to 2005, Nat. Hazards Earth Syst. Sci., 6, 505-518, 2006, http://www.nat-hazards-earth-syst-sci.net/6/505/2006/.

Barriendos, M. and Martín Vide, J.: Meteorological hazards in Barcelona as from historical records (from the 14th to the 19th century). Initial results concerning their plurisecular climatic patter", in:Advances in Historical Climatology in Spain, edited by: Martín Vide, J., Oikos-Tau, Barcelona, 133-156, 1997.

Barriendos, M., Coeur, D., Lang, M., Llasat, M. C., Naulet, R., Lemaitre, F., and Barrera, A.: Stationarity analysis of historical flood series in France and Spain (14th-20th centuries), Nat. Hazards Earth Syst. Sci., 3, 583-592, 2003,

http://www.nat-hazards-earth-syst-sci.net/3/583/2003/.

Brilly, M. and Polic, M.: Public perception of flood risks, flood forecasting and mitigation, Nat. Hazards Earth Syst. Sci., 5, 345355,2005 , http://www.nat-hazards-earth-syst-sci.net/5/345/2005/.

Buizza, R., Hollingsworth, A., Lalaurette, F., and Ghelli, A.: Probabilistic Predictions of Precipitation Using the ECMWF Ensemble Prediction System, Weather and Forecasting, 14, 168-189, 1998.

Chancibault, K., Anquetin, S., Ducrocq, V., Saulnier, G.-M.: Hydrological evaluation of high resolution precipitation forecasts of the Gard flash-flood event (8-9 September 2002), Q. J. Roy. Meteorol. Soc., 132, 1091-1117, 2006.

Collier, C. G.: Flash flood forecasting: What are the limits of predictability?, Q. J. Roy. Meteorol. Soc., 133, 3-23, 2007.

Cutter, S. L.: Living with risk, The geography of technological hazards, Arnold, London-New York, 214 pp., 1993.

Cullen, A. C. and Frey, H. C.: Probabilistic Techniques in Exposure Assessment - A Handbook for Dealing with Variability and Uncertainty in Models and Inputs, Plenum Press, New York, 1999.

Diomede, T., Nerozzi, F., Paccagnella, T., and Todini, E.: The use of meteorological analogues to account for LAM QPF uncertainty, Hydrol. Earth Syst. Sci., 12, 141-157, 2008, http://www.hydrol-earth-syst-sci.net/12/141/2008/.

Enander A.: Risk perception in a wider context: how do the results from FLOWS fit with other studies on risk perception?, FLOWS Third International Conference, Conference report, 2005.

Estrela, T., Marcuello, C., and Dimas, M.: Las aguas continentales en los países mediterráneos de la Unión Europea, Report of the
CEDEX, Ministerio de Fomento, Madrid, Spain, 293 pp., 2000.

Ferraris, L., Rudari, R., and Siccardi, F.: The Uncertainty in the Prediction of Flash Floods in the Northern Mediterranean Environment, J. Hydrometeorol. 3(6), 714-727, 2002.

Fiori, E., Parodi, A., and Siccardi, F.: Dealing with uncertainty: turbulent parameterizations and grid-spacing effects in numerical modelling of deep moist convective processes, Nat. Hazards Earth Syst. Sci., 9, 1871-1880, 2009, http://www.nat-hazards-earth-syst-sci.net/9/1871/2009/.

Fordham, M. H.: Choice and Constraint in Flood Hazard Mitigation: The Environmental Attitudes of Floodplain Residents and Engineers, PhD Thesis, Middlesex University, 1992.

Gabellani, G., Boni, G., Ferraris, L., Hardenberg, J. H., and Provenzale, A.:. Propagation of uncertainty from rainfall to runoff: A case study with a stochastic rainfall generator, Adv. Water Resour., 30, 2061-2071, ISSN: 0309-1708, 2007.

Garcia-Moya, J. A., Callado, A., Santos, C., Santos-Munoz, D., and Simarro, J.: Multimodel Ensemble for Operational Short-Range Forecast. 9th Plinius Conference on Mediterranean Storms, Varenna, Italy, October, p. 18, 2008.

Guzzetti, F., Cardinali, M., and Reichenbach, P.: The AVI Project: A bibliographical and archive inventory of landslides and floods in Italy, Environ. Manage., 18, 623-633, 1994.

Kundzewicz, Z. W. and Mendel, L.: Flood risk and vulnerability in the changing world, International conference: Towards natural flood reduction strategies, Warsaw, 2003.

Lastoria, B., Simonetti, M. R., Casaioli, M., Mariani, S., and Monacelli, G.: Socio-economic impacts of major floods in Italy from 1951 to 2003, Adv. Geosci., 7, 223-229, 2006, http://www.adv-geosci.net/7/223/2006/.

Legrand, P., Brugnot, G., and Baumont, G.: Rétour d'experience des inondations de septembre de 2002 dans les départaments du Gard, de l'Hérault, du Vaucluse, des Bouches de Rhône, de l'Ardèche et de la Drôme, Contribution du Groupe d'Appui et d'expertisse scientifique, (CD-ROM), 2003.

Llasat, M. C.: Les crues mediterraneennes recentes et historiques (Espagne, France, Italie), consequences-enseignements-projets. Crues extremes regionaux en Europe, La Houille Blanche, 6, 3741, 2004.

Llasat, M. C.: High magnitude storms and floods, in: The Physical Geography of the Mediterranean, edited by: Woodward, J. C., Oxford University Press, Oxford, 513-540, 2009.

Llasat-Botija, M. and Llasat, M. C.: Comparaison des systèmes d'alerte opérationnels, Espagne, France, Italie, Projet AMPHORE, 2003-03-4.3-I-079, Interreg III B Mediterranée occidentale, 2006.

Llasat, M. C., López, L., Barnolas, M., and Llasat-Botija, M.: Flash-floods in Catalonia: the social perception in a context of changing vulnerability, Adv. Geosci., 17, 63-70, 2008, http://www.adv-geosci.net/17/63/2008/.

Llasat, M. C., Atencia, A., Garrote, L., and Mediero, L.: The hydrometeorological forecasting in the framework of the European project FLASH, La Houille Blanche, 6, 66-71, doi:10.1051/lhb/2009080, 2009.

Martín, M. L., Santos-Muñoz, D., Morata, A., Luna, M. Y., and Valero, F.: An objectively selected case study of a heavy rain event in the Mediterranean Basin: A diagnosis using numerical simulation, Atmos. Res., 81, 187-205, 2006.

Messner, F. and Meyer, V.: Flood damage, vulnerability and risk 
perception. Challenges for flood damage research, in: Flood Risk Management: Hazards, Vulnerability and Mitigation Measures, edited by: Schanze, J., Zeman, E., and Marsalek, J., Springer, 149-167, 2006.

Molini, L., Parodi, A., Rebora, N., and Siccardi, F.: Assessing uncertainty in radar measurements on simplified meteorological scenarios, Adv. Geosci., 7, 141-146, 2006, http://www.adv-geosci.net/7/141/2006/.

Molini, L., De Sanctis, K., Parodi, A., Ferretti, R., Marzano, F. S., Montopoli, M., and Siccardi, F.: Characterization of convective rainfall using c-band dual-polarizedradar and models intercomparison: COSMO-LAMI and MM5, 4th European Conference on Severe Storms, 10-14 September 2007, Trieste, Italy, 2007.

Morin, E., Goodrich, D. C., Maddox, R. A., Gao, X., Gupta, H. V., and Sorooshian, S.: Spatial patterns in thunderstorm rainfall events and their coupling with watershed hydrological response, Adv. Water Resour., 29, 843-860, 2006.

Munich Re: Topics: Geo Natural Catastrophes, Münchener Rück, 2007.

Nunes Correia, F., Fordham, M., Saraiva, M., and Bernardo, F.: Flood Hazard Assessment and Management: Interface with the Public, Water Resour. Manage., 12, 209-227, 1998.

Raiable, C. C., Della-Marta, P. M., Schwierz, C., Wernli, H., and Blender, R.: Northern Hemisphere Extratropical Cyclones: A Comparison of Detection and Tracking Methods and Different Reanalyses, Mon. Weather Rev., 136, 880-897, 2008.

Ramos, M. H., Bartholmes, J., and Thielen-del Pozo, J.: Development of decision support products based on ensemble weather forecasts in the European Flood Alert System, Atmos. Sci.. Lett., 8, 113-119, 2007.

Richard, E., Cosma, S., Benoit, R., Binder, P., Buzzi, A., and Kaufmann, P.: Intercomparison of mesoscale meteorological models for precipitation forecasting, Hydrol. Earth Syst. Sci., 7, 799811,2003 , http://www.hydrol-earth-syst-sci.net/7/799/2003/.

Rife, D. L., Davis, C. A., Liou, Y. L., and Warner, T. T.: Predictability of Low-Level Winds by Mesoscale Meteorological Models, Mon. Weather Rev., 132(11), 2553-2569, 2004.

Rotunno, R.: Moist convection and mesoscale predictability, 9th Plinius Conference on Mediterranean Storms, Varenna, Italy, October, p. 15, 2008.

Siccardi, F., Boni, G., Ferraris, L., and Rudari, R.: A HydroMeteorological Approach for Probabilistic Flood Forecast, J. Geophys. Res., 110, D5, doi:10.1029/2005JD005787, 2005.

Siccardi, F. and Tibaldi, S.: Proscenio first year Report, Dept. of Civil Protection, Rome, 2006.
Skiple Ibreek, A., Krasovkaia, I., Gottschalk, L., and Berg, H.: Perception and communication of flood risk - preliminary results from the flows project, International Conference on Innovation Advances and Implementation of Flood Forecasting Technology, Norway, 2005.

Steppeler, J., Hess, R., Doms, G., Schattler, U., and Bonaventura, L.: Review of numerical methods for non hydrostatic weather prediction models, Meteorol. Atmos. Phys., 82, 287-301, 2003.

Turato, B., Reale, O., and Siccardi, F.: Water Vapor Sources of the October 2000 Piedmont Flood, J. Hydrometeorol., 5, 693-712, 2004.

UNISDR: World Conference on Disaster Reduction. Proceedings of the Conference. Building the Resilience of Nations and Communities to Disasters, 18-22 January 2005, Kobe, Hyogo, Japan, United Nations, Geneva, http://documents.un.org/simple. asp, 2005.

UNISDRa: Disasters in numbers, http://www.unisdr.org/eng/ terminology/terminology-2009-eng.html, 2009.

UNISDRb: UNISDR Terminology on Disaster Risk Reduction, http://www.unisdr.org/eng/, 2009.

Vincendon, B., Chancibault, K., Ducrocq, V., Bouilloud, L., Saulnier, G.-M., Lelay, M., Kotroni, V., Lagouvardos, K., Milelli, M., Rabuffetti, D., and Dierer, S.: Flash flood forecasting within the preview project: high resolution hydrometeorological simulations, http://www.cnrm.meteo.fr/icam2007/ /ICAM2007/extended/manuscript_178.pdf, 2007.

von Hardenberg, J., Ferraris, L., Rebora, N., and Provenzale, A.: Meteorological uncertainty and rainfall downscaling, Nonlin. Processes Geophys., 14, 193-199, 2007, http://www.nonlin-processes-geophys.net/14/193/2007/.

Wilson, L.: Comments on "Probabilistic Predictions of Precipitation Using the ECMWF Ensemble Prediction System", Weather and Forecasting, 15, 361-364, 2000.

Wood, E. F. and Rodriguez-Iturbe, I.: A Baysian approach to analyzing uncertainty among flood frequency models, Water Resour. Res., 11, 839-843, 1975.

Zampieri, M., Malguzzi, P., and Buzzi, A.: Sensitivity of quantitative precipitation forecasts to boundary layer parameterization: a flash flood case study in the Western Mediterranean, Nat. Hazards Earth Syst. Sci., 5, 603-612, 2005, http://www.nat-hazards-earth-syst-sci.net/5/603/2005/. 